\title{
Effects of Fresh Watermelon Consumption on the Acute Satiety Response and Cardiometabolic Risk Factors in Overweight and Obese Adults
}

\author{
Tiffany Lum, Megan Connolly, Amanda Marx, Joshua Beidler, Shirin Hooshmand, Mark Kern, \\ Changqi Liu $\mathbb{D}$ and Mee Young Hong*
}

School of Exercise and Nutritional Sciences, San Diego State University, San Diego, CA 92182, USA; tiffanynlum@gmail.com (T.L.); megcconnolly@gmail.com (M.C.); amandamarx27@gmail.com (A.M.); beidler@gmail.com (J.B.); shooshmand@sdsu.edu (S.H.); kern@sdsu.edu (M.K.); changqi.liu@sdsu.edu (C.L.)

* Correspondence: mhong2@sdsu.edu; Tel.: +1-619-594-2392

Received: 11 February 2019; Accepted: 6 March 2019; Published: 12 March 2019

\begin{abstract}
Although some studies have demonstrated the beneficial effects of watermelon supplementation on metabolic diseases, no study has explored the potential mechanism by which watermelon consumption improves body weight management. The objective of this study was to evaluate the effects of fresh watermelon consumption on satiety, postprandial glucose and insulin response, and adiposity and body weight change after 4 weeks of intervention in overweight and obese adults. In a crossover design, 33 overweight or obese subjects consumed watermelon ( 2 cups) or isocaloric low-fat cookies daily for 4 weeks. Relative to cookies, watermelon elicited more $(p<0.05)$ robust satiety responses (lower hunger, prospective food consumption and desire to eat and greater fullness). Watermelon consumption significantly decreased body weight, body mass index (BMI), systolic blood pressure and waist-to-hip ratio $(p \leq 0.05)$. Cookie consumption significantly increased blood pressure and body fat $(p<0.05)$. Oxidative stress was lower at four week of watermelon intervention compared to cookie intervention $(p=0.034)$. Total antioxidant capacity increased with watermelon consumption $(p=0.003)$ in blood. This study shows that reductions in body weight, body mass index (BMI), and blood pressure can be achieved through daily consumption of watermelon, which also improves some factors associated with overweight and obesity (clinicaltrials.gov, NCT03380221).
\end{abstract}

Keywords: watermelon; satiety; oxidative stress; antioxidant; human

\section{Introduction}

Obesity, which affects $39.8 \%$ of U.S. adults, contributes to numerous health problems, including cardiovascular disease, hypertension, type II diabetes, and other leading causes of mortality [1,2]. Common treatments for obesity include medications and diets that restrict total calories or specific macronutrients. However, obesity medications are associated with adverse effects, and only about one-fifth of dieters maintain their weight loss for at least one year [3,4]. In light of the serious health consequences of obesity and the limited success of current therapies, there is an urgent need for new approaches.

Healthful snacking may be a simpler and more sustainable approach to improving dietary quality, increasing satiety, and combating weight gain. Over a 40-year period, self-reported eating behaviors of adults demonstrated increased energy intake when snacks were consumed between lunch and dinner or eaten in place of meals [5]. Therefore, choosing snacks that are lower in calories could contribute to a significant reduction in total energy intake. As a snack, fruit is palatable and convenient, and has 
generally been associated with lower body weight in epidemiological studies [6]. The tendency of fruit to promote a healthy body weight may result from its high water and fiber content, which results in a lower energy density compared with many other popular snack foods [7]. Because people tend to eat a consistent weight of food during a meal or snack, selecting foods that are lower in energy density can lead to greater satiety and lower total energy intake [7].

Fruit has been associated with greater satiety [8-10] and lower subsequent energy intake [9-11] compared with refined carbohydrate snacks. Although the effects of watermelon on satiety and body weight have not been investigated, watermelon is a strong candidate to promote satiety because its high water content results in a lower energy density than most fruits. One cup of diced watermelon contains only 46 kilocalories but meets $21 \%$ of the daily requirement for vitamin $C$ and $17 \%$ of the daily requirement for vitamin A [12]. In addition to aiding in weight management, fruit snacks can improve diet quality [13]. Replacing conventional snack foods with watermelon could increase intake of potassium and dietary fiber, which are under-consumed, while reducing intake of added sugars and saturated and trans fats, which are consumed in excess [14]. Watermelon has been described as a functional food due to its possible health benefits [15]. Red-fleshed watermelon varieties are rich in lycopene, a carotenoid that may protect against cancer and cardiovascular disease [16]. Watermelon is also the richest food source of L-citrulline, a non-essential amino acid that functions as a precursor for nitric oxide synthesis [17]. Watermelon consumption has been linked to lower blood pressure in humans [17] and improved blood lipid profile in animals and humans [18-21].

The purpose of this study was to compare the effects of watermelon and an isocaloric low-fat cookie snack on body weight, appetitive sensations, postprandial glucose and insulin, and appetite-regulating hormone concentrations. To determine the effects of chronic watermelon consumption, physiological and metabolic outcomes were measured before and after four weeks of the two snacks. Additionally, acute effects were determined by measuring perceived appetite sensations and blood concentrations of glucose, insulin, and appetite-regulating hormones before and up to $120 \mathrm{~min}$ after consumption of the two snacks. We hypothesized that watermelon consumption would reduce body weight by increasing perceived satiety and moderating postprandial glucose and insulin responses compared with an isocaloric low-fat cookie snack.

\section{Materials and Methods}

\subsection{Participants}

Overweight and obese adults (males $n=20$, females $n=13$ ) between the ages of 18 and 55 years with a body mass index (BMI) of $25-40 \mathrm{~kg} / \mathrm{m}^{2}$ were recruited in Southern California. Exclusion criteria included pregnancy, smoking, any medical problems or metabolic disorders that might alter appetite or body weight, and allergies to or dislike of watermelon (WM) or any ingredient in low-fat cookies (LFC) such as gluten, milk protein, and eggs. Individuals who were actively dieting or engaged in weight loss activities were also excluded, as were women with irregular menstrual cycles. The study was approved by the San Diego State University Institutional Review Board. Potential participants were screened for eligibility criteria, and informed written consent was obtained (clinicaltrials.gov, NCT03380221).

\subsection{Study Design}

This study utilized a crossover design with two 4-week dietary interventions separated by a 2-4 week washout period to prevent carryover effects. Based on a previous human trial of watermelon [22], power analysis (G*Power, Germany) indicated that significant differences would be detected with a sample of 33 subjects at $75 \%$ power and an alpha-level of $p<0.05$. Eligible participants $(n=33)$ were assigned to a 4-week repeated measures crossover with two treatments given-a WM snack followed by a 2-4 week washout period, and then crossed over to an isocaloric-matched LFC snack. Subjects visited the lab at baseline and after 4 weeks for each intervention. Female participants 
started each trial at day 3 to 11 of their menstrual cycles. Visits occurred in the morning after a 10-h overnight fast. Height and weight (Detecto weigh beam eye-level; Webb City, MO, USA), body fat (dual-energy X-ray absorptiometry, Prodigy, GE Healthcare, Chicago, IL, USA), waist circumference, hip circumference, and blood pressure (Omron M3; Kyoto, Japan) were assessed for each visit.

During the baseline visits, each subject was instructed on completion of a visual analogue scale (VAS) to assess baseline appetite [23]. Blood samples were collected, then subjects were instructed to consume 2 cups of fresh WM (92 kcal) or isocaloric LFC (92 kcal, Nilla Wafers Reduced Fat, Nabisco, East Hanover, NJ, USA) along with $8 \mathrm{fl}$. Oz of water in the laboratory. Postprandial responses were measured by administering new VAS to subjects at 20, 40, 60, 90, and 120 min following snack consumption. A second blood sample was collected $60 \mathrm{~min}$ post-snack consumption. Blood samples were centrifuged at $1200 \times g$ for $10 \mathrm{~min}$ at $4{ }^{\circ} \mathrm{C}$ and serum samples were stored at $-80^{\circ} \mathrm{C}$ until analysis.

During the WM intervention, participants consumed 2 cups of fresh diced WM (92 kcal) daily for 4 weeks. During the LFC intervention, participants consumed Nabisco vanilla wafer cookies (92 kcal) daily for 4 weeks. Each WM serving contained $92 \mathrm{kcal}, 23 \mathrm{~g}$ carbohydrate, $2 \mathrm{~g}$ protein, $0 \mathrm{~g}$ fat, and $1 \mathrm{~g}$ fiber. Each LFC serving contained $92 \mathrm{kcal}, 18.2 \mathrm{~g}$ carbohydrate, $0.76 \mathrm{~g}$ protein, $1.14 \mathrm{~g}$ fat, and $0 \mathrm{~g}$ fiber. Participants could consume their snacks at any time of day, during one or multiple sittings, alone or in combination with other foods in order to resemble snacking conditions in everyday life. Participants were asked to avoid consuming LFC during the WM intervention and to avoid consuming WM during the LFC intervention, in order to keep the potential effects of the two snacks separate. Aside from the daily consumption of either snack, participants were instructed to maintain their typical dietary intakes and physical activity levels. At the end of each four-week intervention, fasting blood samples were collected.

\subsection{Satiety Questionnaire}

The visual analogue scale (VAS) [23] measured appetite responses by asking a series of 5 questions assessing hunger, fullness, desire to eat, prospective food consumption, and thirst. Each question was followed by a $10 \mathrm{~cm}$ line with words anchored at each end, expressing the lowest $(0 \mathrm{~cm})$ and highest $(10 \mathrm{~cm})$ ratings of each. Subjects could record their responses by marking a spot on the line indicating their feelings about each question. Responses were quantified by measuring the distance from the left end of the line to the designated mark.

\subsection{Dietary Assessment and Physical Activity}

Dietary intake was measured using 24-h dietary recalls on the two days preceding the in-laboratory visit by trained staff. The United States Department of Agriculture (USDA) Supertracker (2012) was used to evaluate average daily energy intakes. Physical activity levels were also assessed using a validated Physical Activity Recall (PAR) Questionnaire [24].

\subsection{Postprandial Glucose and Insulin Response}

Serum glucose was measured using a colorimetric glucose assay kit (Stanbio Laboratory, Boerne, TX, USA) and analyzed according to the manufacturer's instructions. A reagent containing glucose oxidase was mixed with the serum samples in cuvettes, resulting in the formation of hydrogen peroxide. The hydrogen peroxide then reacted to form a quinone complex. The absorbance of the quinone complex was read at $500 \mathrm{~nm}$.

Insulin was measured with a sandwich enzyme-linked immunosorbent assay (ELISA) kit (ALPCO, Salem, NH, USA). The serum samples and secondary antibody were added to the insulin-specific antibody coated wells. A 3,3',5,5'-tetramethylbenzidine (TMB) substrate was added to the wells to produce color and the plates were incubated a second time. Lastly, a stop solution was added and the plates were measured spectrophotometrically at $450 \mathrm{~nm}$. 


\subsection{Appetite-Regulating Hormones}

The appetite-regulating hormones leptin, ghrelin, adiponectin, and cholecystokinin (CCK) were assayed using ELISA kits (RayBiotech, Norcross, GA, USA). In each assay, the target hormone in the samples was bound by immobilized antibodies. A biotinylated antibody was added, followed by horseradish peroxidase-conjugated streptavidin, and finally a substrate solution that developed color in proportion to the amount of hormone bound. Following the addition of stop solution, the plates were measured spectrophotometrically at $450 \mathrm{~nm}$.

\subsection{C-Reactive Protein}

C-reactive protein (CRP) was measured using an ELISA kit (Calbiotech, Spring Valley, CA, USA) and analyzed per the manufacturer's instructions. Microplates were coated with monoclonal antibodies to CRP. The serum samples and anti-CRP-horseradish-peroxidase conjugated secondary antibody were added to the microplate wells. TMB substrate was added to produce color. The plates were incubated, stop solution was added, and absorbance was measured at $450 \mathrm{~nm}$.

\subsection{Serum Lipids}

Blood lipid profiles were analyzed using serum triglyceride (TG), total cholesterol (TC) and high-density lipoprotein cholesterol (HDL-C) (Stanbio Laboratory, Boerne, TX, USA) colorimetric assay kits. Low-density lipoprotein cholesterol (LDL-C) was calculated using the following equation: LDL cholesterol $=$ total cholesterol - HDL cholesterol - (triglycerides/5) [25].

\subsection{Thiobarbituric Acid Reactive Substances (TBARS)}

Lipid peroxidation as a marker of oxidative stress was analyzed using a thiobarbituric acid reactive substances (TBARS) assay kit (Cayman Chemical Company, Ann Arbor, MI, USA). The assay standards were prepared with malondialdehyde. The standards and serum samples were mixed with sodium dodecyl sulfate solution in vials, then the thiobarbituric acid was added. Vials were boiled for $1 \mathrm{~h}$, and then placed in an ice bath. Samples were centrifuged and pipetted into microplate wells. Absorbance was measured at $535 \mathrm{~nm}$.

\subsection{Catalase Activity}

Catalase activity, a marker of antioxidant capacity, was analyzed using a catalase assay kit (Cayman Chemical Company). Serum samples were mixed with hydrogen peroxide to initiate the formation of formaldehyde. Potassium hydroxide was added to stop the reaction and chromogen was added for colorimetric measurement of formaldehyde production. Catalase potassium periodate was added, then absorbance was read at $540 \mathrm{~nm}$.

\subsection{Total Antioxidant Capacity}

Total antioxidant capacity (TAC) was analyzed using an antioxidant assay kit (Cayman Chemical Company). Standards were prepared using Trolox. The standards and serum samples were mixed with metmyoglobin and chromogen and then hydrogen peroxide was added to initiate the reactions. Inhibition of the oxidation of 2,2'-Azino-di-(3-ethylbenzothiazoline sulphonate) (ABTS) by metmyoglobin was measured by reading the absorbance at $405 \mathrm{~nm}$ using a spectrophotometer.

\subsection{Liver Function Markers}

Alkaline phosphatase (ALP), alanine aminotransferase (ALT), aspartate aminotransferase (AST), creatine kinase $(\mathrm{CK})$, and lactate dehydrogenase $(\mathrm{LDH})$ were determined in serum samples using assay kits from Stanbio (Boerne, TX, USA). All assays were performed according to the manufacturer's instructions. ALP was read at $405 \mathrm{~nm}$ and the other enzyme assays were read at $340 \mathrm{~nm}$. 


\subsection{Statistical Analysis}

The normality of the data was checked using the explore function in SPSS (SPSS Statistics version 24, IBM, Armonk, NY, USA). When data showed a normal distribution, two-way repeated measures ANOVA were used to analyze the effects of WM and LFC treatments on each of the variables over time, as well as any significant interactions between snack type and time. If the interaction was significant, a least significant difference (LSD) analysis was used for post-hoc comparison. When normality assumption was suspect, a nonparametric Wilcoxon analysis was performed. Data were considered statistically significant when $p<0.05$.

\section{Results}

\subsection{Body Weight and Blood Pressure}

Significant interactions were found for body weight (Interaction $p=0.005$; Snack effect $p=0.064$; Time effect $p=0.730$ ) and BMI (Interaction $p=0.006$; Snack effect $p=0.061$; Time effect $p=0.799$ ). Body weight and BMI values did not differ significantly between the two interventions at baseline, but were significantly lower after four weeks of WM consumption and significantly higher after four weeks of LFC consumption compared with baseline values (Table 1). Four weeks of WM consumption did not change systolic blood pressure (SBP) and diastolic blood pressure (DBP), but four weeks of LFC consumption significantly increased both SBP $(p=0.015)$ and DBP $(p=0.001)$. Waist-to-hip ratio was lowered at week four of WM consumption compared with week for of LFC consumption ( $p=0.019)$. Body fat percentage did not change significantly over the course of the WM intervention but was significantly higher at week four of the LFC intervention than at baseline $(p=0.005)$. Dietary intake of total energy, carbohydrate, protein, fat and dietary fiber, and moderate and hard physical activity were not different between the trials.

Table 1. Effects of snacks on body weight, body mass index (BMI), blood pressure, waist-to-hip ratio, and body fat of participants at baseline and week 4 for each intervention.

\begin{tabular}{ccccc}
\hline \multirow{2}{*}{ Measurements } & \multicolumn{2}{c}{ Watermelon $(n=33)$} & \multicolumn{2}{c}{ Cookies $(n=33)$} \\
\cline { 2 - 5 } & Baseline & Week 4 & Baseline & Week 4 \\
\hline Body Weight $(\mathrm{kg})$ & $89.4 \pm 15^{\mathrm{a}}$ & $88.9 \pm 16^{\mathrm{b}}$ & $89.3 \pm 16^{\mathrm{a}}$ & $89.9 \pm 16^{\mathrm{c}}$ \\
BMI & $30.5 \pm 3.5^{\mathrm{a}}$ & $30.4 \pm 3.7^{\mathrm{b}}$ & $30.5 \pm 3.7^{\mathrm{a}}$ & $30.7 \pm 3.8^{\mathrm{c}}$ \\
SBP (mm Hg) & $127 \pm 15^{\mathrm{a}, \mathrm{b}}$ & $125 \pm 14^{\mathrm{a}}$ & $124 \pm 14^{\mathrm{a}}$ & $129 \pm 14^{\mathrm{b}}$ \\
DBP (mm Hg) & $79.9 \pm 7.2^{\mathrm{a}}$ & $79.6 \pm 9.7^{\mathrm{a}}$ & $77.2 \pm 9.0^{\mathrm{b}}$ & $81.2 \pm 10^{\mathrm{a}}$ \\
W / H ratio & $0.850 \pm 0.06^{\mathrm{a}, \mathrm{b}}$ & $0.845 \pm 0.07^{\mathrm{a}}$ & $0.847 \pm 0.07^{\mathrm{a}, \mathrm{b}}$ & $0.857 \pm 0.07^{\mathrm{b}}$ \\
Body Fat $(\%)$ & $37.8 \pm 8.2^{\mathrm{a}}$ & $38.0 \pm 8.5^{\mathrm{a}}$ & $37.7 \pm 8.2^{\mathrm{a}}$ & $38.2 \pm 7.9^{\mathrm{b}}$ \\
\hline
\end{tabular}

Data are presented as means \pm SD. Data within rows with varying superscript letters are statistically different $(p<0.05) . n=33$ (20 males / 13 females). BMI, body mass index; SBP, systolic blood pressure; DBP, diastolic blood pressure; $\mathrm{W} / \mathrm{H}$ ratio, waist-to-hip ratio.

\subsection{Appetite}

The VAS response curves for hunger, fullness, desire to eat, prospective food consumption, and thirst are presented in Figure 1 for both WM and LFC snacks. For hunger, WM produced lower ratings of hunger for up to 90-min post-consumption compared with baseline, while LFC significantly reduced hunger for only up to 20-min post-consumption (Figure 1A). Feelings of hunger were significantly greater for LFC compared with WM at 20, 40, 60, and $90 \mathrm{~min}(p<0.05)$ (Figure 1a). Participants were significantly more full between baseline and 90-min for WM, and from baseline to 40-min for LFC (Figure 1b). Feelings of fullness were significantly greater for WM compared with LFC from 20-min to 90-min post-consumption $(p<0.05$ ) (Figure $1 b)$. Compared with baseline, desire to eat was significantly reduced up to 90-min post-WM consumption, while LFC only reduced the desire to eat for up to 20-min post-consumption (Figure 1c). Desire to eat was significantly greater for LFC compared with WM at 
all time points after consumption of snacks $(p<0.05)$ (Figure 1c). Similar to desire to eat, prospective food consumption was significantly reduced for up to $90-\mathrm{min}$ post-WM consumption compared with baseline, while there were no differences for the LFC at any of the time points (Figure 1d). Prospective food consumption significantly differed between snacks up to 90-min post-consumption $(p<0.05)$ (Figure 1d). Thirst was significantly reduced at 20-min compared with baseline for both WM and LFC, while feelings of thirst were significantly reduced after WM consumption compared with LFC consumption at 20 and 40-mins $(p<0.05)$ (Figure 1e).



(a)

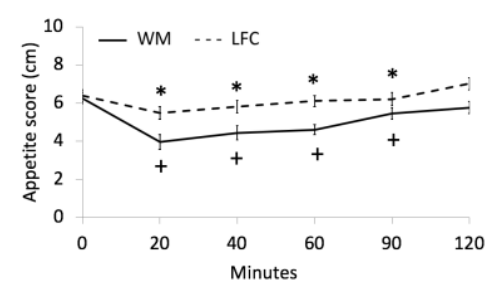

(d)



(b)

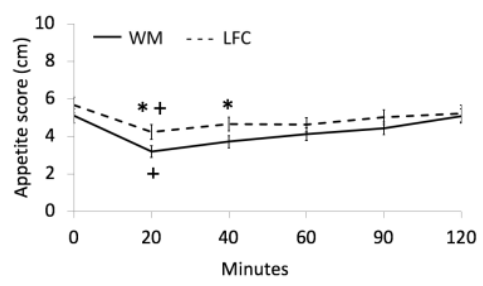

(e)

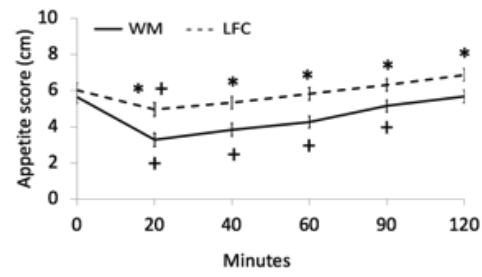

(c)

Figure 1. Effects of watermelon (WM) and low-fat cookies (LFC) on (a) hunger, (b) fullness, (c) desire to eat, (d) prospective food consumption, and (e) thirst. *: different between WM and LFC; +: different from baseline. VAS: visual analogue scale.

\subsection{Glucose and Insulin}

No significant differences in blood glucose concentrations were found between snacks at baseline or at $1-\mathrm{h}$ postconsumption. Furthermore, there was no change in blood glucose at $1-\mathrm{h}$ postconsumption compared with baseline for either snack (Figure 2a). Blood insulin levels significantly increased for both snacks 1-h postconsumption compared with baseline $(p<0.05)$, but no significant differences were found between snacks (Figure 2b). Following the four-week interventions, serum glucose levels were not significantly different between the WM and LFC interventions. There were also no significant changes in serum glucose between baseline $(5.10 \pm 1.36 \mathrm{mmol} / \mathrm{L}$ vs. $5.20 \pm 1.20 \mathrm{mmol} / \mathrm{L})$ and week four $(5.59 \pm 1.90 \mathrm{mmol} / \mathrm{L}$ vs. $5.10 \pm 0.90 \mathrm{mmol} / \mathrm{L})$ within each intervention. Similarly, serum insulin levels were not significantly different between the WM and LFC interventions at baseline $(25.4 \pm 2.1 \mathrm{mIU} / \mathrm{L}$ vs. $27.4 \pm 1.8 \mathrm{mIU} / \mathrm{L})$ or week four $(27.5 \pm 2.0 \mathrm{mIU} / \mathrm{L}$ vs. $26.8 \pm 2.0 \mathrm{mIU} / \mathrm{L})$ and did not change significantly from baseline to week four within each intervention. 


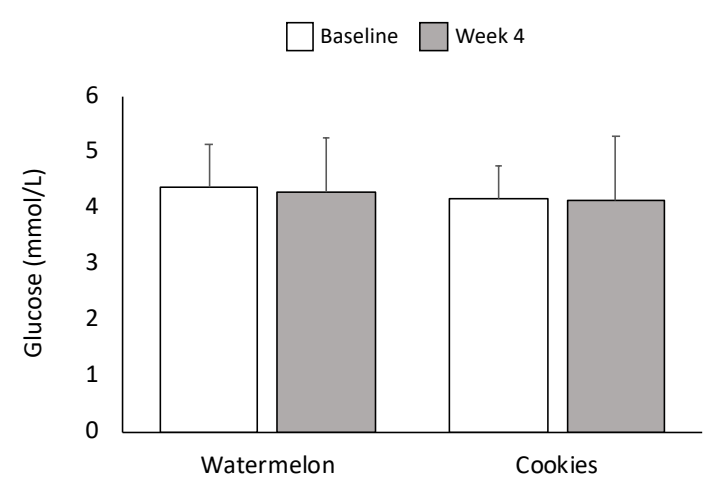

(a)



(b)

Figure 2. (a) Effects of WM and LFC on postprandial glucose. No significant differences in blood glucose were observed between snacks and between pre-consumption (pre) and 1-h postconsumption (post). (b) Effects of WM and LFC on postprandial insulin. Blood insulin significantly increased $(p<0.05)$ in both snacks 1 -h postconsumption compared with baseline. Data are presented as means \pm SD. Within a variable, values not sharing common superscript are significantly different at $p<0.05$.

\subsection{Appetite-Regulating Hormones}

The appetite-regulating hormones leptin, ghrelin, adiponectin, and CCK were measured in blood samples taken at the baseline fasted state and 1-h after snack consumption (Table 2). WM reduced leptin levels $(p=0.017)$, and LFC showed a trend to reduce leptin $(p=0.057)$. WM resulted in higher ghrelin $(p=0.004)$, and LFC tended to increase ghrelin levels $(p=0.086)$. There was a trend toward higher adiponectin concentration after WM consumption $(p=0.055)$.

Table 2. Effects of WM or LFC consumption on postprandial satiety hormone.

\begin{tabular}{ccccc}
\hline & \multicolumn{2}{c}{ Watermelon $(\boldsymbol{n}=\mathbf{3 3})$} & \multicolumn{2}{c}{ Cookies $(\boldsymbol{n}=\mathbf{3 3})$} \\
\cline { 2 - 5 } & Pre & Post & Pre & Post \\
\hline Leptin $(\mathrm{ng} / \mathrm{mL})$ & $3.65 \pm 2.02^{\mathrm{a}}$ & $3.28 \pm 2.01^{\mathrm{b}}$ & $3.71 \pm 1.96^{\mathrm{a}}$ & $3.42 \pm 2.07^{\mathrm{a}, \mathrm{b}}$ \\
Ghrelin $(\mathrm{pg} / \mathrm{mL})$ & $414 \pm 246^{\mathrm{a}}$ & $520 \pm 356^{\mathrm{b}}$ & $424 \pm 250^{\mathrm{a}}$ & $511 \pm 352^{\mathrm{a}, \mathrm{b}}$ \\
Adiponectin $(\mu \mathrm{g} / \mathrm{mL})$ & $9.93 \pm 5.81$ & $10.66 \pm 5.08$ & $9.20 \pm 5.63$ & $8.41 \pm 6.33$ \\
CCK $(\mathrm{pg} / \mathrm{mL})$ & $465 \pm 242$ & $514 \pm 170$ & $495 \pm 178$ & $542 \pm 207$ \\
\hline
\end{tabular}

Values are means \pm SD. $n=33$ (20 males/13 females). Data within rows with varying superscript letters are statistically different $(p<0.05)$.

\subsection{C-Reactive Protein}

Serum CRP as an indicator of chronic inflammation was not significantly different between the WM and LFC interventions at baseline $(7.21 \pm 3.37 \mathrm{mg} / \mathrm{L}$ vs. $7.14 \pm 2.94 \mathrm{mg} / \mathrm{L})$ or week four $(7.07 \pm 3.18 \mathrm{mg} / \mathrm{L}$ vs. $7.19 \pm 3.36 \mathrm{mg} / \mathrm{L})$ and did not differ significantly over time within each intervention.

\subsection{Serum Lipids}

Lipid profiles are shown below in Figure 3. WM consumption significantly lowered TG $(p=0.046)$. TC was significantly lower after four weeks of the WM intervention compared with LFC ( $p=0.024)$. WM consumption significantly increased HDL-C $(p=0.046)$, while there was a trend toward lower HDL-C following LFC consumption $(p=0.066)$. LDL cholesterol decreased significantly after four weeks of WM consumption and increased significantly after four weeks of LFC consumption $(p=0.011)$. 


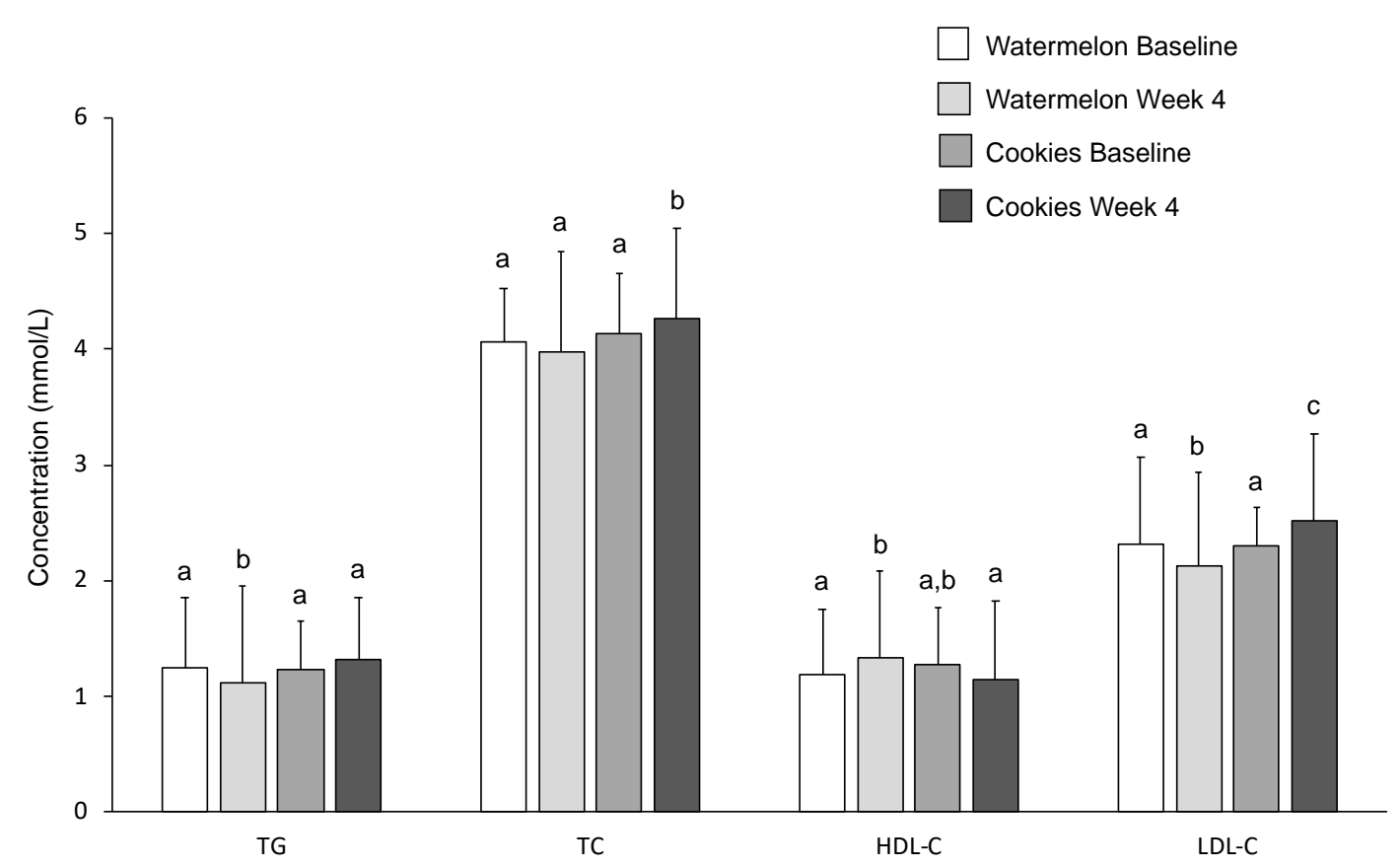

Figure 3. Effects of WM and LFC on serum concentrations of triglycerides (TG), total cholesterol (TC), high-density lipoprotein cholesterol (HDL-C), and low-density lipoprotein cholesterol (LDL-C) at baseline and week 4 of each intervention. Data are presented as means $\pm S D$. Within a variable, values not sharing a common superscript are significantly different at $p<0.05$.

\subsection{Oxidative Stress and Antioxidant Capacity}

After four weeks of WM treatment, there was a trend toward lower TBARS, an indicator of lipid peroxidation $(p=0.091)$. The LFC intervention showed a trend toward higher lipid peroxidation from baseline to week four $(p=0.092)$ (Figure 4a). Lipid peroxidation was lower at four week of WM intervention compared to four weeks of LFC intervention $(p=0.034)$. Levels of catalase, an antioxidant enzyme, were not significantly different between the two interventions. Total antioxidant capacity did not change significantly after four weeks of LFC consumption but increased significantly after four weeks of WM consumption ( $p=0.003$ ) (Figure $4 \mathrm{~b}$ ).



(a)

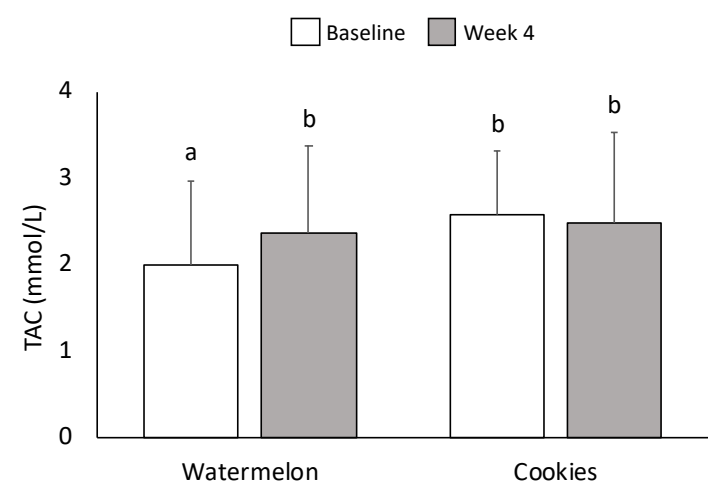

(b)

Figure 4. Effects of WM and LFC on serum values for (a) thiobarbituric acid reactive substances (TBARS) and (b) total antioxidant capacity (TAC) at baseline and week 4 of each intervention. Data are presented as means $\pm \mathrm{SD}$. Within a variable, values not sharing a common superscript are significantly different at $p<0.05$. 


\subsection{Liver Function Markers}

There were no significant differences in the liver function markers AST, ALT, ALP, LDH, or CK after four weeks of the WM and LFC interventions.

\section{Discussion and Conclusions}

As a natural food that provides fiber, micronutrients, and bioactive phytochemicals, watermelon may be a healthier alternative to conventional snacks. This study compared the effects of consuming watermelon versus an isocaloric low-fat cookie snack for four weeks on body weight, blood pressure, glucose and insulin concentrations, and biomarkers for inflammation, oxidative stress, and liver function. In addition, the acute effects of the two snacks were determined by measuring perceived appetite, blood glucose, insulin, and appetite-regulating hormone concentrations for up to 120 min post-consumption.

After four weeks, body weight and BMI increased in the LFC trial and decreased in the watermelon trial. Only a few intervention studies have compared a fruit snack with a processed snack, and none showed significant effects on body weight or other measures of adiposity $[11,26,27]$. Watermelon consumption has been associated with reduced weight gain and fat mass in some animal studies [18,28]. In humans, however, watermelon feeding studies with a duration of up to six weeks have not reported changes in body weight or body composition [21,22,29-32]. A possible explanation for these divergent results is that prior studies used watermelon juice or reconstituted watermelon powder, whereas our study used whole watermelon flesh. Whole fruit has been shown to promote greater satiety than juice [33]. This effect could be attributed to higher fiber content, which promotes satiety and reduces energy intake [34,35]. However, Flood-Obbagy and Rolls found that whole apples were more satiating than apple juice or applesauce, despite having similar fiber content [33]. Whole fruit has greater volume and requires more chewing than other forms, which could affect food intake by initiating cephalic-phase responses related to digestion and metabolism [33]. In addition, subject expectations that solid foods are more filling than juice may contribute to the satiating effects of whole fruit [33].

Acute watermelon consumption resulted in significantly greater satiety ratings than the LFC snack. The watermelon snack left subjects feeling significantly less hungry compared with baseline for up to two hours after snack consumption, while the LFC snack only reduced hunger for up to $20 \mathrm{~min}$. Compared with the LFC snack, the watermelon snack had significantly greater volume due to its high water content. The volume of food can contribute to increased satiety through such factors as perception of the amount of food being consumed, time spent consuming food, rate of gastric emptying, and degree of gastric distension [36,37]. The sensory and hedonic characteristics of food such as sight, smell, texture, and taste can also influence palatability and satiety [38]. Appetite ratings reflect subjective feelings of satiety, and therefore concentrations of hunger and satiety hormones may provide better insight into the mechanisms controlling hunger and fullness. Watermelon consumption tended to increase adiponectin, which may partially explain the higher satiety effects of watermelon consumption.

Because the watermelon snack contained almost twice as much total sugar (17 g) as the LFC snack $(9 \mathrm{~g})$, it would be expected to produce a higher postprandial glucose concentration. However, postprandial glucose and insulin were not significantly different between the two snacks. In previous studies, fruit produced smaller increases in blood glucose $[8,39,40]$ and insulin $[8,39,41]$ compared with processed foods. Although the watermelon snack contains sugar, the total load was quite low; therefore, the blood glucose concentrations apparently returned to normal within one hour. Additionally, watermelon possesses other nutritional components that may have suppressed a rise in blood glucose. Watermelon contains a small amount of dietary fiber, which can improve glucose tolerance [42]. What is likely of greater importance is that more than half of the total sugars in watermelon consist of fructose, which has little effect on blood glucose levels [12,39]. In fact, co-ingestion of fructose and glucose blunts the glycemic response to glucose, possibly by enhancing hepatic glucose uptake $[39,43,44]$. A meta-analysis showed that moderate intakes of up to $36 \mathrm{~g} /$ day 
of fructose (less than the $10.3 \mathrm{~g}$ in two cups of watermelon) resulted in lower fasting glucose and hemoglobin $\mathrm{A} 1 \mathrm{c}(\mathrm{HbA} 1 \mathrm{c})$ without causing elevated triglycerides [45]. Adiponectin levels were not significantly different between the trials, although there was a trend toward increased postprandial adiponectin following watermelon consumption. Adiponectin is a hormone secreted by adipose tissue that is paradoxically more abundant in obese than in lean individuals, and circulating levels increase after weight reduction $[46,47]$. As adiponectin increases insulin sensitivity, the trend toward increased postprandial adiponectin following watermelon consumption may suggest a glucose-stabilizing effect.

After four weeks, the watermelon intervention showed a trend toward lower SBP compared with baseline. In contrast, both SBP and DBP were higher after four weeks of LFC consumption. Several previous studies have shown greater decreases in SBP and DBP with watermelon supplementation compared with a refined carbohydrate control [22,29-31,48]. Watermelon is the richest natural source of L-citrulline, a nonessential amino acid that may be responsible for watermelon's hypotensive effects [17]. L-citrulline is readily converted to L-arginine, and oral L-citrulline intake has been shown to raise circulating L-arginine levels [49]. In turn, endothelial nitric oxide synthase (eNOS) converts L-arginine to nitric oxide, which induces vascular smooth muscle relaxation [17].

Four weeks of watermelon consumption resulted in an improved blood lipid profile, including lower levels of TG and LDL-C and higher levels of HDL-C. Following the LFC intervention, TG and LDL-C increased and HDL-C trended lower. One prior human study showed that six weeks of supplementation with watermelon extract reduced TC and LDL-C compared with a carbohydrate beverage [21]. Several animal studies have also shown beneficial effects of watermelon consumption on TC, LDL-C, and TG levels [18-20]. Analysis of hepatic mRNA expression in rats found that watermelon reduced expression of fatty acid synthase (FAS), an enzyme involved in fatty acid synthesis, and HMG-CoA reductase (HMGCR), the rate-limiting enzyme in cholesterol synthesis [20]. These metabolic alterations may have contributed to the improved lipid profile.

Watermelon consumption for four weeks increased antioxidant status and tended to reduce oxidative stress. One previous human study reported increased antioxidant status as indicated by higher ferric reducing ability of plasma (FRAP) and oxygen radical absorbance capacity (ORAC) following two weeks of watermelon supplementation [32]. Watermelon consumption has also been associated with lower oxidative stress and increased antioxidant status in experimental animals [18-20]. These results may be partially explained by increased plasma concentrations of lycopene and other carotenoid antioxidants $[50,51]$. Watermelon's L-citrulline content may also reduce oxidative stress by serving as a substrate for endogenous nitric oxide production [17]. Although nitric oxide is primarily known for its vasodilatory properties, it can also reduce oxidative stress by scavenging or preventing the formation of hydroxyl radicals [52].

An important limitation of this study is the measurement of postprandial response at a single 60-min time point. The current study found no significant differences in postprandial glucose or insulin levels between trials. The protocol may have not been able to detect genuine differences if concentrations of these biomarkers peaked before the second blood draw. In support of this hypothesis, some studies have found glucose to peak approximately $30 \mathrm{~min}$ after fruit consumption and decline thereafter $[8,39]$. For example, in the study by Furchner-Evanson et al., plasma glucose concentrations did not differ significantly between the dried plum and cookie trials at the 60-min timepoint [8]. However, due to the higher values at the 15-, 30-, and 45-min timepoints, the cookie trial produced a significantly higher glucose level that would not have been detected if blood would have been collected only one hour after consumption. Future studies should include more critical time points for measuring satiety hormones-i.e., measurements at the 15-, 30-, and 45-min marks to define postprandial peak. Because the four-week WM trial preceded the LFC trial for all subjects, it is possible that there was an order effect. Subjects were told that the purpose of the study was to compare effects of different snacks on health, but they did not know that the specific focus was on watermelon versus cookies. This aspect of the study design may have reduced the risk of the placebo or order effect. A nested design, in which half the subjects start with watermelon and the other half with LFC, should 
be used to reduce the chance of order effects in the future study. Another limitation is that it is unclear which biochemical components or sensory qualities of watermelon contributed to increased satiety and reduced body weight compared with the LFC control. In order to further investigate these effects, it would be necessary to test whole watermelon against its isolated bioactive components. Finally, it is unknown whether the watermelon dosage was optimal, or whether a larger dosage might have had more significant effects on measured outcomes. Therefore, future studies should compare the effects of different watermelon dosages on satiety and body weight.

In conclusion, watermelon promoted greater satiety than an isocaloric LFC snack for up to $90 \mathrm{~min}$ post-consumption. Additionally, four weeks of watermelon consumption reduced body weight and blood pressure while improving blood lipid profile and antioxidant status. These results suggest that fresh watermelon, when consumed in place of conventional refined carbohydrate snacks, may help reduce appetite and assist with weight management while reducing cardiovascular risk factors.

Author Contributions: T.L., M.C., A.M., S.H., M.K. and M.Y.H. collected the data; T.L., M.C. and M.Y.H. wrote the first draft of the manuscript; S.H., M.K., C.L. and J.B. reviewed and edited the manuscript. All authors reviewed and commented on subsequent drafts of the manuscript.

Funding: This study was funded by the National Watermelon Promotion Board (NWPB 17-18).

Conflicts of Interest: The authors declare no conflict of interest.

\section{References}

1. Hales, C.; Carroll, M.D.; Fryar, C.D.; Ogden, C.L. Prevalence of Obesity among Adults and Youth: United States, 2015-2016. Available online: https:/ / www.cdc.gov/nchs/products/databriefs/db288.htm (accessed on 26 November 2018).

2. Must, A.; McKeown, N.M. The Disease Burden Associated with Overweight and Obesity. In Endotext; De Groot, L.J., Chrousos, G., Dungan, K., Feingold, K.R., Grossman, A., Hershman, J.M., Koch, C., Korbonits, M., McLachlan, R., et al., Eds.; MDText.com, Inc.: South Dartmouth, MA, USA, 2000.

3. Wing, R.R.; Phelan, S. Long-term weight loss maintenance. Am. J. Clin. Nutr. 2005, 82, 222S-225S. [CrossRef] [PubMed]

4. Padwal, R.S.; Majumdar, S.R. Drug treatments for obesity: Orlistat, sibutramine, and rimonabant. Lancet 2007, 369, 71-77. [CrossRef]

5. Piernas, C.; Popkin, B.M. Snacking increased among U.S. adults between 1977 and 2006. J. Nutr. 2010, 140, 325-332. [CrossRef] [PubMed]

6. Boeing, H.; Bechthold, A.; Bub, A.; Ellinger, S.; Haller, D.; Kroke, A.; Leschik-Bonnet, E.; Müller, M.J.; Oberritter, H.; Schulze, M.; et al. Critical review: Vegetables and fruit in the prevention of chronic diseases. Eur. J. Nutr. 2012, 51, 637-663. [CrossRef]

7. Rolls, B.J. The relationship between dietary energy density and energy intake. Physiol. Behav. 2009, 97, 609-615. [CrossRef]

8. Furchner-Evanson, A.; Petrisko, Y.; Howarth, L.; Nemoseck, T.; Kern, M. Type of snack influences satiety responses in adult women. Appetite 2010, 54, 564-569. [CrossRef]

9. Patel, B.P.; Bellissimo, N.; Luhovyy, B.; Bennett, L.J.; Hurton, E.; Painter, J.E.; Anderson, G.H. An after-school snack of raisins lowers cumulative food intake in young children. J. Food Sci. 2013, 78 (Suppl. 1), A5-A10. [CrossRef]

10. Farajian, P.; Katsagani, M.; Zampelas, A. Short-term effects of a snack including dried prunes on energy intake and satiety in normal-weight individuals. Eat. Behav. 2010, 11, 201-203. [CrossRef]

11. Bays, H.; Weiter, K.; Anderson, J. A randomized study of raisins versus alternative snacks on glycemic control and other cardiovascular risk factors in patients with type 2 diabetes mellitus. Phys. Sportsmed. 2015, 43, 37-43. [CrossRef]

12. Nutrient Database Laboratory (U.S.) and Consumer and Food Economics Institute (U.S.). USDA Nutrient Database for Standard Reference. Available online: https://ndb.nal.usda.gov/ndb/ (accessed on 26 November 2018).

13. Barnes, T.L.; French, S.A.; Harnack, L.J.; Mitchell, N.R.; Wolfson, J. Snacking behaviors, diet quality, and body mass index in a community sample of working adults. J. Acad. Nutr. Diet. 2015, 115, 1117-1123. [CrossRef] 
14. U.S. Department of Health and Human Services and U.S. Department of Agriculture. 2015-2020 Dietary Guidelines for Americans, 8th ed.; 2015. Available online: https://health.gov/dietaryguidelines/2015/ resources/2015-2020_dietary_guidelines.pdf (accessed on 26 November 2018).

15. Perkins-Veazie, P.; Davis, A.; Collins, J.K. Watermelon: From dessert to functional food. Isr. J. Plant Sci. 2012, 60, 395-402.

16. Story, E.N.; Kopec, R.E.; Schwartz, S.J.; Harris, G.K. An Update on the Health Effects of Tomato Lycopene. Annu. Rev. Food Sci. Technol. 2010, 1, 189-210. [CrossRef]

17. Figueroa, A.; Wong, A.; Jaime, S.J.; Gonzales, J.U. Influence of L-citrulline and watermelon supplementation on vascular function and exercise performance. Curr. Opin. Clin. Nutr. Metab. Care 2017, 20, 92-98. [CrossRef] [PubMed]

18. Poduri, A.; Rateri, D.L.; Saha, S.K.; Saha, S.; Daugherty, A. Citrullus lanatus "sentinel" (watermelon) extract reduces atherosclerosis in LDL receptor-deficient mice. J. Nutr. Biochem. 2013, 24, 882-886. [CrossRef] [PubMed]

19. Hong, M.Y.; Hartig, N.; Kaufman, K.; Hooshmand, S.; Figueroa, A.; Kern, M. Watermelon consumption improves inflammation and antioxidant capacity in rats fed an atherogenic diet. Nutr. Res. 2015, 35, 251-258. [CrossRef] [PubMed]

20. Hong, M.Y.; Beidler, J.; Hooshmand, S.; Figueroa, A.; Kern, M. Watermelon and L-arginine consumption improve serum lipid profile and reduce inflammation and oxidative stress by altering gene expression in rats fed an atherogenic diet. Nutr. Res. 2018, 58, 46-54. [CrossRef] [PubMed]

21. Massa, N.M.; Silva, A.S.; de Oliveira, C.V.; Costa, M.J.; Persuhn, D.C.; Barbosa, C.V.; Gonçalves, M.D. Supplementation with Watermelon Extract Reduces Total Cholesterol and LDL Cholesterol in Adults with Dyslipidemia under the Influence of the MTHFR C677T Polymorphism. J. Am. Coll. Nutr. 2016, 35, 514-520. [CrossRef] [PubMed]

22. Figueroa, A.; Sanchez-Gonzalez, M.A.; Wong, A.; Arjmandi, B.H. Watermelon extract supplementation reduces ankle blood pressure and carotid augmentation index in obese adults with prehypertension or hypertension. Am. J. Hypertens. 2012, 25, 640-643. [CrossRef]

23. Flint, A.; Raben, A.; Blundell, J.E.; Astrup, A. Reproducibility, power and validity of visual analogue scales in assessment of appetite sensations in single test meal studies. Int. J. Obes. Relat. Metab. Disord. J. Int. Assoc. Study Obes. 2000, 24, 38-48. [CrossRef]

24. Sallis, J.F.; Haskell, W.L.; Wood, P.D.; Fortmann, S.P.; Rogers, T.; Blair, S.N.; Paffenbarger, R.S., Jr. Physical activity assessment methodology in the Five-City Project. Am. J. Epidemiol. 1985, 121, 91-106. [CrossRef]

25. Friedewald, W.T.; Levy, R.I.; Fredrickson, D.S. Estimation of the concentration of low-density lipoprotein cholesterol in plasma, without use of the preparative ultracentrifuge. Clin. Chem. 1972, 18, 499-502.

26. Kaliora, A.C.; Kokkinos, A.; Diolintzi, A.; Stoupaki, M.; Gioxari, A.; Kanellos, P.T.; Dedoussis, G.V.Z.; Vlachogiannakos, J.; Revenas, C.; Ladas, S.D.; et al. The effect of minimal dietary changes with raisins in NAFLD patients with non-significant fibrosis: A randomized controlled intervention. Food Funct. 2016, 7 , 4533-4544. [CrossRef]

27. Kanellos, P.T.; Kaliora, A.C.; Tentolouris, N.K.; Argiana, V.; Perrea, D.; Kalogeropoulos, N.; Kountouri, A.M.; Karathanos, V.T. A pilot, randomized controlled trial to examine the health outcomes of raisin consumption in patients with diabetes. Nutrition 2014, 30, 358-364. [CrossRef]

28. Wu, G.; Collins, J.K.; Perkins-Veazie, P.; Siddiq, M.; Dolan, K.D.; Kelly, K.A.; Heaps, C.L.; Meininger, C.J. Dietary supplementation with watermelon pomace juice enhances arginine availability and ameliorates the metabolic syndrome in Zucker diabetic fatty rats. J. Nutr. 2007, 137, 2680-2685. [CrossRef] [PubMed]

29. Figueroa, A.; Sanchez-Gonzalez, M.A.; Perkins-Veazie, P.M.; Arjmandi, B.H. Effects of watermelon supplementation on aortic blood pressure and wave reflection in individuals with prehypertension: A pilot study. Am. J. Hypertens. 2011, 24, 40-44. [CrossRef] [PubMed]

30. Figueroa, A.; Wong, A.; Hooshmand, S.; Sanchez-Gonzalez, M.A. Effects of watermelon supplementation on arterial stiffness and wave reflection amplitude in postmenopausal women. Menopause 2013, 20, 573-577. [CrossRef]

31. Figueroa, A.; Wong, A.; Kalfon, R. Effects of Watermelon Supplementation on Aortic Hemodynamic Responses to the Cold Pressor Test in Obese Hypertensive Adults. Am. J. Hypertens. 2013, 27, 899-906. [CrossRef]

32. Shanely, R.A.; Nieman, D.C.; Perkins-Veazie, P.; Henson, D.A.; Meaney, M.P.; Knab, A.M.; Cialdell-Kam, L. Comparison of Watermelon and Carbohydrate Beverage on Exercise-Induced Alterations in Systemic Inflammation, Immune Dysfunction, and Plasma Antioxidant Capacity. Nutrients 2016, 8, 518. [CrossRef] 
33. Flood-Obbagy, J.E.; Rolls, B.J. The effect of fruit in different forms on energy intake and satiety at a meal. Appetite 2009, 52, 416-422. [CrossRef]

34. Burton-Freeman, B. Dietary fiber and energy regulation. J. Nutr. 2000, 130, 272S-275S. [CrossRef]

35. Howarth, L.; Petrisko, Y.; Furchner-Evanson, A.; Nemoseck, T.; Kern, M. Snack selection influences nutrient intake, triglycerides, and bowel habits of adult women: A pilot study. J. Am. Diet. Assoc. 2010, 110, 1322-1327. [CrossRef] [PubMed]

36. Żurakowski, A.; Zahorska-Markiewicz, B.; Olszanecka-Glinianowicz, M.; Kocelak, P. Effect of Meal Volume on Hunger and Satiety in Obese Subjects: Volume of meal and satiety. EJIFCC 2006, 17, 167-176. [PubMed]

37. Rolls, B.J.; Bell, E.A.; Waugh, B.A. Increasing the volume of a food by incorporating air affects satiety in men. Am. J. Clin. Nutr. 2000, 72, 361-368. [CrossRef] [PubMed]

38. Sørensen, L.B.; Møller, P.; Flint, A.; Martens, M.; Raben, A. Effect of sensory perception of foods on appetite and food intake: A review of studies on humans. Int. J. Obes. 2003, 27, 1152-1166. [CrossRef] [PubMed]

39. Esfahani, A.; Lam, J.; Kendall, C.W.C. Acute effects of raisin consumption on glucose and insulin reponses in healthy individuals. J. Nutr. Sci. 2014, 3, e1. [CrossRef] [PubMed]

40. Sansone, K.; Kern, M.; Hong, M.Y.; Liu, C.; Hooshmand, S. Acute Effects of Dried Apple Consumption on Metabolic and Cognitive Responses in Healthy Individuals. J. Med. Food 2018, 21, 1158-1164. [CrossRef]

41. Byrne, H.K.; Kim, Y.; Hertzler, S.R.; Watt, C.A.; Mattern, C.O. Glycemic and insulinemic responses to different preexercise snacks in participants with impaired fasting glucose. Int. J. Sport Nutr. Exerc. Metab. 2011, 21, 1-10. [CrossRef]

42. Nilsson, A.C.; Ostman, E.M.; Holst, J.J.; Björck, I.M.E. Including indigestible carbohydrates in the evening meal of healthy subjects improves glucose tolerance, lowers inflammatory markers, and increases satiety after a subsequent standardized breakfast. J. Nutr. 2008, 138, 732-739. [CrossRef]

43. Moore, M.C.; Cherrington, A.D.; Mann, S.L.; Davis, S.N. Acute fructose administration decreases the glycemic response to an oral glucose tolerance test in normal adults. J. Clin. Endocrinol. Metab. 2000, 85, 4515-4519. [CrossRef]

44. Moore, M.C.; Davis, S.N.; Mann, S.L.; Cherrington, A.D. Acute fructose administration improves oral glucose tolerance in adults with type 2 diabetes. Diabetes Care 2001, 24, 1882-1887. [CrossRef]

45. Sievenpiper, J.L.; Chiavaroli, L.; de Souza, R.J.; Mirrahimi, A.; Cozma, A.I.; Ha, V.; Wang, D.D.; Yu, M.E.; Carleton, A.J.; Beyene, J.; et al. 'Catalytic' doses of fructose may benefit glycaemic control without harming cardiometabolic risk factors: A small meta-analysis of randomised controlled feeding trials. Br. J. Nutr. 2012, 108, 418-423. [CrossRef]

46. Jazet, I.M.; Pijl, H.; Meinders, A.E. Adipose tissue as an endocrine organ: Impact on insulin resistance. Neth. J. Med. 2003, 61, 194-212.

47. English, P.J.; Coughlin, S.R.; Hayden, K.; Malik, I.A.; Wilding, J.P.H. Plasma adiponectin increases postprandially in obese, but not in lean, subjects. Obes. Res. 2003, 11, 839-844. [CrossRef]

48. Massa, N.M.L.; Silva, A.S.; Toscano, L.T.; Silva, J.D.R.; Persuhn, D.C.; Gonçalves, M.D.C.R. Watermelon extract reduces blood pressure but does not change sympathovagal balance in prehypertensive and hypertensive subjects. Blood 2016, 25, 244-248.

49. Kuhn, K.; Harris, P.; Cunningham, G.; Robbins, I.; Summar, M.; Christman, B. Oral citrulline effectively elevates plasma arginine levels for $24 \mathrm{~h}$ in normal volunteers. Circ. AHA Sci. Sess. 2006, II, 1339.

50. Kim, C.-H.; Park, M.-K.; Kim, S.-K.; Cho, Y.-H. Antioxidant capacity and anti-inflammatory activity of lycopene in watermelon. Int. J. Food Sci. Technol. 2014, 49, 2083-2091. [CrossRef]

51. Edwards, A.J.; Vinyard, B.T.; Wiley, E.R.; Brown, E.D.; Collins, J.K.; Perkins-Veazie, P.; Baker, R.A.; Clevidence, B.A. Consumption of watermelon juice increases plasma concentrations of lycopene and beta-carotene in humans. J. Nutr. 2003, 133, 1043-1050. [CrossRef]

52. Wink, D.A.; Miranda, K.M.; Espey, M.G.; Pluta, R.M.; Hewett, S.J.; Colton, C.; Vitek, M.; Feelisch, M.; Grisham, M.B. Mechanisms of the Antioxidant Effects of Nitric Oxide. Antioxid. Redox Signal. 2001, 3, 203-213. [CrossRef]

(C) 2019 by the authors. Licensee MDPI, Basel, Switzerland. This article is an open access article distributed under the terms and conditions of the Creative Commons Attribution (CC BY) license (http:/ / creativecommons.org/licenses/by/4.0/). 